\title{
Miyelodisplastik Sendromlu Olguların Kan ve Kemik İliği Örneklerinin Konvansiyonel Sitogenetik ve Floresan İn Situ Hibridizasyon (FISH) Yöntemiyle İncelenmesi
}

\section{Investigation of Blood and Bone Marrow Samples of Patients with Myelodysplastic Syndrome by Conventional Cytogenetic and Fluorescent In Situ Hybridization Methods}

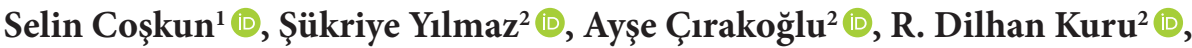 \\ Yelda Tarkan Argüden ${ }^{2}$ (D), Şeniz Öngören ${ }^{3}$ (D), Seniha Hacıhanefioğlu ${ }^{2}$
}

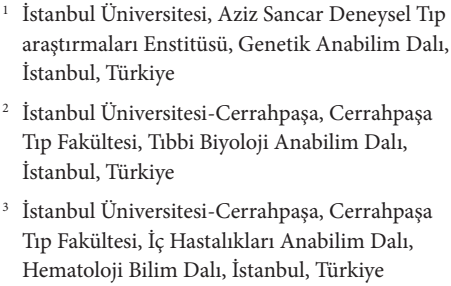
araştırmaları Enstitüsü, Genetik Anabilim Dalı, İstanbul, Türkiye

2 İstanbul Üniversitesi-Cerrahpaşa, Cerrahpaşa Tip Fakültesi, Tıbbi Biyoloji Anabilim Dalı, İstanbul, Türkiye

3 İstanbul Üniversitesi-Cerrahpaşa, Cerrahpaşa Tıp Fakültesi, İç Hastalıkları Anabilim Dalı, Hematoloji Bilim Dalı, İstanbul, Türkiye

ORCID: S.C. 0000-0001-8200-7633;

S..Y. 0000-0001-8076-3080;

A.Ç. 0000-0003-0330-2277;

R.D.K. 0000-0001-8088-5336;

Y.T.A. 0000-0002-5405-3365;

Ş.Ö. 0000-0002-2809-5510;

S.H. 0000-0002-1817-0994

Corresponding author/Sorumlu yazar: Ayșe Çırakoğlu,

İstanbul Üniversitesi-Cerrahpaşa, Cerrahpaşa Tip Fakültesi, Tibbi Biyoloji Anabilim Dalı,

İstanbul, Türkiye

E-mail: aysecirakoglu@yahoo.com

Submitted/Geliș tarihi: 10.09.2020 First Revision Received/Ilk revizyon: 11.09.2020 Last Revision Received/Son revizyon: 01.10.2020 Accepted/Kabul Tarihi: 07.10.2020

Citation/Atıf: Coskun S, Yilmaz S, Cırakoglu A, Kuru RD, Tarkan Arguden Y, Ongoren S, et al. Investigation of blood and bone marrow samples of patients with myelodysplastic syndrome by conventional cytogenetic and fluorescent in situ hybridization methods. Sağlık Bilimlerinde İleri Araștırmalar Dergisi 2020; 3(3): 122-129. https://doi.org/10.26650/JARHS2020-793043

\section{ÖZ}

Amaç: Miyelodiplastik sendrom (MDS) olgularının \%30-50'sinde kromozom anomalileri gözlenmektedir. En sık gözlenen anomaliler trizomi 8, monozomi 7/7q-, monozomi 5/5qve $20 \mathrm{q}$ - olarak belirlenmiştir. $\mathrm{Bu}$ anomalilerin saptanmasında konvansiyonel sitogenetik ve interfaz FISH (iFISH) yöntemleri kullanılmaktadır. Her iki yöntem için tercih edilen materyal kemik iliği olmakla birlikte, perifer kanının kullanılmasının uygunluğu da araştırılmaktadır. $\mathrm{Bu}$ çalışmada, laboratuvarımıza başvuran MDS hastalarının perifer kanı ve kemik iliği örneklerindeki anomalilerin sitogenetik ve iFISH yöntemleri ile karşılaştırılarak mevcut veri havuzuna katkı sağlanması amaçlanmıştır.

Gereç ve Yöntem: MDS tanılı 19 olgunun perifer kanı ve kemik iliği örnekleri konvansiyonel sitogenetik ve $5 \mathrm{q} 31,7 \mathrm{q} 22$ ve $7 \mathrm{q} 31$ bölgelerine özgü delesyon problarının kullanıldığ iFISH yöntemleriyle incelenerek, elde edilen veriler örnek tipi ve kullanılan yönteme göre karşılaştırılmıştır.

Bulgular: Konvansiyonel sitogenetik yöntemiyle olguların 5 'inde periferik kan ve kemik iliği örneklerinde elde edilen sonuçlar arasında (iki olguda normal, üç olguda anormal karyotip) konkordans, 12 olguda diskordans gözlenmiş, iki olguda kemik iliğinde metafaz elde edilemezken, perifer kanında klonal sayı anomalileri saptanmıștır. iFISH yöntemiyle incelemede ise, olguların perifer kanı ve kemik iliği örnekleri arasında, $-5 / \operatorname{del}(5 q)$ incelemesinde 13 olguda (iki olguda pozitif, 11 olguda negatif), -7/del(7q) için 10 olguda (bir olguda pozitif, 9 olguda negatif) konkordans gözlenmiştir. Sitogenetik olarak tek olgunun kemik iliği örneğinde birlikte gözlenen del(5q) ve del(7q) bulguları, hem perifer kanı hem de kemik iliği örneklerinde uygulanan iFISH analizinde de pozitif olarak saptanmıștır.

Sonuç: Elde ettiğimiz sonuçlar daha önce bildirilen çalışmalarla birlikte değerlendirildiğinde her iki yöntem ve her iki örnek tipinin kendilerine özgü avantajlara ve dezavantajlara sahip oldukları gözlenmiştir. Bu durum bu iki yöntem ve örneğin birbirlerinin yerini almak yerine, paralel olarak kullanılmalarının yararlı olacağını düşündürmektedir. Anahtar Kelimeler: Miyelodisplastik Sendrom, Sitogenetik, interfaz FISH

\section{ABSTRACT}

Objective: Chromosome abnormalities are observed in 30-50\% of myelodysplastic syndrome (MDS) cases. The most common anomalies are trisomy 8 , monosomy $7 / 7 \mathrm{q}$ monosomy 5 / 5q- and 20q-. Conventional cytogenetic and interphase FISH methods are used to detect these anomalies. Although bone marrow is the preferred material for both methods, the suitability of using peripheral blood is also being investigated. The aim of this study is to contribute to the data pool in this area by presenting comparative cytogenetic and interphase FISH examination results in peripheral blood and bone marrow samples of MDS patients who applied to our laboratory.

Materials and Methods: Peripheral blood and bone marrow samples of 19 patients with MDS were examined with conventional cytogenetic and iFISH methods using deletion probes specific to the $5 \mathrm{q} 31,7 \mathrm{q} 22$ and $7 \mathrm{q} 31$ regions. The data obtained were used to compare the materials and techniques. 
Results: Conventional cytogenetics: In this technique, the results of peripheral blood and bone marrow samples were concordant in 5 cases (normal karyotypes in 2, and abnormal in 3 cases), and discordant in 12 cases, and in two cases, there was no metaphase in bone marrow samples, while abnormal karyotypes were observed in blood samples. iFISH: Between the results of peripheral blood and bone marrow; for $-5 / \mathrm{del}(5 \mathrm{q})$ there was concordance in 13 cases (positive in two, and negative in three cases), and for $-7 / \mathrm{del}(7 \mathrm{q}$ ), 10 cases were concordant (positive in one, and negative in 9 cases). The one case that del(5q) and del(7q) were observed together in conventional cytogenetic examination, was positive in iFISH analysis for both anomalies, too.

Conclusion: When we evaluate our results together with previous reports, it seems that both methods and both materials have their own advantages and disadvantages. Therefore, we suggest that it would be beneficial to use these two methods and materials in parallel instead of replacing each other.

Keywords: Myelodysplastic syndrome, Cytogenetics, interphase FISH 


\section{GİRIŞ}

Miyelodisplastik sendrom (MDS) yetersiz ve displastik hematopoez ile karakterize, klonal bir hematolojik hastalıktır. Kemik iliğinde hiperselülarite ve blast hücre artışı olmasına karşın, perifer kanında sitopeni gözlenir (1). MDS'li hastaların klinik fenotipi çok çeşitlidir. $\mathrm{Bu}$ çeşitlilik, sitopenilerin ağırlığı, kemik iliğindeki hücre zenginliği ve blast sayısı, Akut miyeloid lösemiye (AML) dönüşme oranı, sağkalım ve tedaviye yanıt gibi durumlarla ilişkilidir. Fenotipik heterojenitenin sebebi, hastalığın patogenezinde büyük bir rol oynayan genetik değişimlerin çeşitliliğidir $(1,2)$.

Kromozomal değişimler MDS’nin \%30-50'sinde görülür. Bu değişimler dengeli translokasyonlar, sayısal veya yapısal artış ya da kayıplara sahip dengesiz karyotipler olabileceği gibi kompleks karyotipler de olabilir (3). Trizomi 8 , monozomi 7/7q-, monozomi $5 / 5 q$ - ve 20q- MDS'de en sık gözlenen anomalilerdir (4).

Konvansiyonel sitogenetik yöntemler, MDS kliniğinin sitogenetik değerlendirilmesinde altın standart olarak değerlendirilse de bazı sınırlamaları vardır. $\mathrm{Bu}$ incelemeler için neoplastik klonun bölünebilen hücrelerine ihtiyaç vardır ve bazı durumlarda metafaz hücrelerinin azlığı nedeniyle sonuçları yorumlamak kolay değildir. İnterfaz flüoresan in situ hibridizasyon (iFISH) yöntemi ise mitotik indeksin düşük olduğu durumlarda, bölünen hücrelere ihtiyaç duymadan interfaz hücrelerinde spesifik anomalilerin tanımlanmasını sağlar. iFISH'in başka bir avantajı, konvansiyonel sitogenetiğe göre daha fazla hücre analiz edilmesinden dolayı, yüksek hassasiyete sahip olmasıdır (5).

MDS'de gözlenen kromozom anomalilerinden bazıları tedavi seçiminde etkili olmaktadır. Bunlardan en önemlisi 5q delesyonudur. İzole 5q delesyonuna sahip MDS hastalarında uygulanan Lenalidomide tedavisi hastaların \%20-45'inde tam sitogenetik yanıt sağlamaktadır. Diğer bir önemli anomali olan 7q delesyonunun ise hastalığın kötü prognozu ile ilişkili olduğu bilinmektedir $(6,7)$.

MDS hastalarında sitogenetik ve iFISH incelemeleri için çoğunlukla kemik iliği örneği kullanılmaktadır. Ancak, kemik iliği aspirasyonu hasta için zor ve acı veren bir işlem olup, hiposelüler veya myelo- fibröz gelişen hastalarda da sıkıntılı olmaktadır. Perifer kanının kemik iliği yerine kullanılmasının uygun olup olmadığının, hem konvansiyonel sitogenetik hem de iFISH yöntemleri kullanılarak araştırıldığı, sınırlı sayıdaki çalışmaların $(8,9,10)$ bazılarında kemik iliği ve perifer kan sonuçlarının iyi korelasyon gösterdiği bildirilmişse de (8) perifer kanının sitogenetik ve iFISH için tam güvenilir bir örnek olmayabileceği, fakat kemik iliği aspirasyonu gerçekleştirilemediği veya yeterli hücre elde edilemediği durumlarda yararlı olabileceği görüşünde birleşilmektedir $(8,9,10)$.

$\mathrm{Bu}$ çalışmayla, laboratuvarımıza başvuran MDS hastalarının perifer kanı ve kemik iliği örneklerinde karşılaştırmalı sitogenetik ve iFISH inceleme sonuçlarını sunarak bu alandaki sınırlı veri havuzuna katkıda bulunmayı amaçladık. Çalışmamızda, MDS hastalarından alınan perifer kanı ve kemik iliği aspirasyonu örneklerinde konvansiyonel sitogenetik analizleri yapıldı ve MDS'de sık gözlenen -5/del5q ve -7/ del7q delesyonlarını belirlemek için 5q31, 7q22 ve $7 q 31$ bölgelerine özgü probları kullanılarak iFISH yöntemi uygulandi.

\section{GEREÇ VE YÖNTEM}

Çalışmamızda, 2012-2014 yılları arasında hematoloji servisine başvuran, MDS tanılı 19 olgunun perifer kanı ve kemik iliği örnekleri konvansiyonel sitogenetik ve iFISH yöntemleriyle incelendi. Sekiz kadın ve 11 erkek hastadan oluşan olgu grubuna ait klinik özellikler Tablo 1'de özetlenmiştir. Bu çalışma için kurumumuz Klinik Araştırmalar Etik Kurulu’ndan etik kurul onayı ve olgulardan bilgilendirilmiş onam formu alınmıştır.

Sitogenetik inceleme için, perifer kanında 72 saatlik, kemik iliğinde 24 ve 48 saatlik kültür ve G-bantlama yöntemleri uygulandı. Elde edilen metafazlar "International System for Human Cytogenomic Nomenclature (ISCN) 2016" kurallarına göre değerlendirildi (11). Sitogenetik incelemede, perifer kan örneğinde en az 20, kemik iliğinde en az 10 metafaz değerlendirildi.

Olguların perifer kan ve kemik iliklerine, $5 \mathrm{q} 31$ bölgesine özgü del(5q) Delesyon Probu (Cytocell Aquarius) ve, 7q22 ve 7q31 bölgelerine özgü del(7q) De- 
Tablo 1. Olgulara ait yaş, cinsiyet, öntanı, tanı ve tedavi bilgileri

\begin{tabular}{|c|c|c|c|c|}
\hline Olgu No & Yaş & Cinsiyet & Tanı & Tedavi \\
\hline 1 & 66 & $\mathrm{E}$ & MDS & \\
\hline 2 & 80 & $\mathrm{~K}$ & * & $\star$ \\
\hline 3 & 60 & $\mathrm{E}$ & $\begin{array}{l}\text { MDS/ } \\
\mathrm{KMPH}\end{array}$ & $\begin{array}{l}\text { EPO kullanımı } \\
\text { AML'ye dönü- } \\
\text { şüm var. } \\
\text { Steradin-İdaru- } \\
\text { bisin }\end{array}$ \\
\hline 4 & 62 & $\mathrm{E}$ & MDS & $\begin{array}{l}\text { Tedavisiz takip } \\
\text { edilen hasta }\end{array}$ \\
\hline 5 & 65 & $\mathrm{E}$ & MDS-RA & * \\
\hline 6 & 64 & $\mathrm{E}$ & $\begin{array}{c}\text { MDS-RA- } \\
\text { EB-I-II }\end{array}$ & $\begin{array}{c}\text { Azasitidin } \\
\text { Transplantasyon } \\
\text { planlanyyor. }\end{array}$ \\
\hline 7 & 66 & K & MDS & $\begin{array}{l}\text { Tedavisiz takip } \\
\text { edilen hasta }\end{array}$ \\
\hline 8 & 56 & K & * & * \\
\hline 9 & 77 & K & MDS & * \\
\hline 10 & 54 & $\mathrm{E}$ & MDS & $\begin{array}{c}\text { Transfüzyon } \\
\text { Azasitidin } \\
\text { Steradin-İdaru- } \\
\text { bisin } \\
\text { Kemik iliği nakli } \\
\text { Remisyon }\end{array}$ \\
\hline 11 & 52 & K & MDS & $\begin{array}{l}\text { Tedavisiz takip } \\
\text { edilen hasta }\end{array}$ \\
\hline 12 & 75 & E & MDS & $\begin{array}{l}\text { Tedavisiz takip } \\
\text { edilen hasta }\end{array}$ \\
\hline 13 & 78 & $\mathrm{E}$ & MDS & $\star$ \\
\hline 14 & 47 & $\mathrm{E}$ & MDS & * \\
\hline 15 & 69 & K & $\begin{array}{l}\text { MDS-RA- } \\
\text { EB-I }\end{array}$ & $\begin{array}{c}\text { Transfüzyon } \\
\text { Azasitidin }\end{array}$ \\
\hline 16 & 61 & $\mathrm{E}$ & $\begin{array}{c}\text { MDS/ } \\
\text { KMPH }\end{array}$ & * \\
\hline 17 & 66 & K & * & * \\
\hline 18 & 43 & $\mathrm{E}$ & MDS & $\begin{array}{c}\text { B-vit } \\
\text { Folik asit }\end{array}$ \\
\hline 19 & 59 & K & MDS & * \\
\hline
\end{tabular}

lesyon Probları (Cytocell Aquarius) kullanılarak iFISH tekniği uygulandı ve 100-300 interfaz nükleusu incelendi. Problara ait eşik ("cut off") değerlerini belirlemek için 20 sağlıklı bireyin perifer kan örneklerine de iFISH yöntemi uygulandı ve elde edilen sonuçlardan eşik değeri BETA.INV yöntemiyle hesaplandı (12).

\section{BULGULAR}

MDS tanısı alan ve yaşları 43-80 arasında değişen $8(\% 42)$ kadın ve 11 (\%58) erkek hastada medyan yaş
64 olarak saptandı. Olgulara ait 19 kemik iliği, 19 perifer kanı olmak üzere toplam 38 örnekte yapılan sitogenetik incelemede iki kemik iliği örneğinde yeterli sayı ve kalitede metafaz elde edilemezken, perifer kan örneklerinin tümünde sonuç elde edildi. Olguların konvansiyonel sitogenetik ve iFISH analiz sonuçları Tablo 2'de yer almaktadır. Bu sonuçlara göre perifer kan örneklerinin 4'ünde, kemik iliği örneklerinin 8 'inde normal karyotip bulundu. Olguların ikisinde hem kan hem de kemik iliğinde normal karyotip saptanırken, diğer olgularda en az bir örnek tipinde klonal anomaliler gözlendi. Üç olguda (Olgu 6, 13, 15) aynı kromozom anomalileri hem kan hem kemik iliğinde gözlenirken, 4 olguda (Olgu 5, 9, 10, 17) iki örnekte farklı klonal anomaliler saptandı. Kemik iliğinde yeterli metafaz elde edilemeyen iki olguda (Olgu 1 ve 16) perifer kanda klonal anomaliler gözlendi.

Sitogenetik analiz sonucunda perifer kanında gözlenen klonal kromozom sayı anomalileri -X, -18 (4'er olguda), -19 (3 olguda), -21, -22 (2'şer olguda), $-Y,-7,-12,-17$ (birer olguda); yapı anomalileri ise 2 olguda del(6)(q11q14), birer olguda del(2)(p21p23?), $\operatorname{add}(4)(q 35), \operatorname{del}(4)(q 31 \mathrm{q} 33$ ?) ve $\operatorname{add}(5)(q 31)$ iken, kemik iliğinde saptanan sayı anomalileri; - Y (2 olguda), birer olguda $-X,+8,-17,-18$; yapı anomalileri, del(6)(q11q14) (2 olguda), idic(X), add(4)(q35), $\operatorname{add}(5)(\mathrm{q} 31), \operatorname{del}(5)(\mathrm{q} 23), \operatorname{del}(7)(\mathrm{q} 22), \operatorname{del}(15)(\mathrm{q} 21)$, del(18)(p11.2) ve del(20)(q11) (birer olguda) olarak tespit edildi.

5q31, 7q22 ve 7q31 bölgelerine özgü problar ile 20 sağlıklı bireyin perifer kan örneklerinde yapılan iFISH analizleri sonucunda, hem -5/del(5q) için, hem de -7/del(7q) için eşik değer \%7 olarak belirlendi. Olguların perifer kanlarında yapılan iFISH incelemeleri sonucunda, 8 olguda $-5 / \operatorname{del}(5 q), 7$ olguda $-7 /$ $\operatorname{del}(7 q)$ sonuçları eşik değerinin üzerinde bulundu. Kemik iliği örneklerinde, -5/del(5q) için eşik değerini iki, -7/del(7q) için 4 olgunun aştığı gözlendi. İki olguda, her iki örnekte de -5/del(5q) saptanırken -7/ $\operatorname{del}(7 q)$ için bu durum sadece bir olguda gözlendi (Tablo 2).

Sitogenetik olarak tek olgunun (Olgu 19) kemik iliği örneğinde kompleks karyotip içinde birlikte gözlenen $\operatorname{del}(5 q)$ ve $\operatorname{del}(7 q)$ bulguları, hem perifer kanı 
Tablo 2. Olgulara ait konvansiyonel sitogenetik ve FISH sonuçları

\begin{tabular}{|c|c|c|c|c|c|c|}
\hline \multirow{3}{*}{$\begin{array}{c}\text { Olgu } \\
\text { no }\end{array}$} & \multicolumn{3}{|c|}{ Perifer kanı } & \multicolumn{3}{|c|}{ Kemik iliği } \\
\hline & \multirow[t]{2}{*}{ Karyotip } & \multicolumn{2}{|c|}{ FISH } & \multirow[t]{2}{*}{ Karyotip } & \multicolumn{2}{|c|}{ FISH } \\
\hline & & $-5 / \operatorname{del}(5 q)$ & $-7 /$ del7q & & $-5 / \operatorname{del}(5 q)$ & $-7 /$ del7q \\
\hline 1 & $45, \mathrm{X},-\mathrm{Y}[3] / 46, \mathrm{XY}[18]$ & - & - & * & - & - \\
\hline 2 & $44 \sim 45, X,-X[c p 4] / 46, X X[6]$ & - & - & $46, \mathrm{XX}[12]$ & - & - \\
\hline 3 & $\begin{array}{c}\text { 45 46,XY,del }(4)(\mathrm{q} 31 \mathrm{q} 33 ?) \\
{[\mathrm{cp} 3] / 43 \sim 44, \mathrm{XY},-7[\mathrm{cp} 3] /} \\
46, \mathrm{XY}[15]\end{array}$ & - & + & $46, \mathrm{XY}[8]$ & - & - \\
\hline 4 & $\begin{array}{c}45 \sim 46, \mathrm{XY}, \operatorname{del}(2)(\mathrm{p} 21 \mathrm{p} 23 ?) \\
{[\mathrm{cp} 3] / 46, \mathrm{XY}[18]}\end{array}$ & - & - & $46, \mathrm{XY}[13]$ & - & - \\
\hline 5 & $\begin{array}{c}30 \sim 45<2 \mathrm{n}>, \mathrm{XY},-17[3],-18[4] \\
,-19[4],-21[5] \\
-22[3][\mathrm{cp} 10] / 46, \mathrm{XY}[14]\end{array}$ & - & - & $\begin{array}{c}45, \mathrm{X},-\mathrm{Y}[4] / 47, \mathrm{XY},+8[3] / \\
46, \mathrm{XY}[3]\end{array}$ & - & - \\
\hline 6 & $\begin{array}{l}\text { 46,XY,del(6)(q11q14)[3]/ } \\
\text { 46,XY[22] }\end{array}$ & + & + & $\begin{array}{c}\text { 44 46,XY,del(6) (q11q14) } \\
\text { [cp6]/ 46,XY[13] }\end{array}$ & - & - \\
\hline 7 & $\begin{array}{c}\text { 39 44,XX,-19[cp3]/ } \\
46, \mathrm{XX}[13]\end{array}$ & - & + & $46, \mathrm{XX}[5]$ & - & - \\
\hline 8 & $\begin{array}{c}38 \sim 45, \mathrm{XX},-\mathrm{X}[3],-21[4],-22[3] \\
{[\mathrm{cp} 7] / 46, \mathrm{XX}[18]}\end{array}$ & + & + & $46, \mathrm{XX}[14]$ & - & - \\
\hline 9 & $42 \sim 45, \mathrm{X},-\mathrm{X}[\mathrm{cp} 5] / 46, \mathrm{XX}[15]$ & - & - & $\begin{array}{c}42 \sim 43, \mathrm{XX},-18[\mathrm{cp} 3] / \\
46, \mathrm{XX}[6]\end{array}$ & - & + \\
\hline 10 & $\begin{array}{c}43 \sim 45, \mathrm{XY},-18[\mathrm{cp} 5] / \\
42 \sim 45, \mathrm{XY},-19[\mathrm{cp} 4] / 46, \mathrm{XY}[9]\end{array}$ & + & - & $\begin{array}{c}45 \sim 46, \mathrm{XY}, \operatorname{del}(18)(\mathrm{p} 11.2) \\
{[\mathrm{cp} 4] / 46, \mathrm{XY}[9]}\end{array}$ & - & - \\
\hline 11 & $46, \mathrm{XX}[28]$ & + & - & $\begin{array}{c}38 \sim 44, \mathrm{XX},-17[\mathrm{cp} 3] / \\
46, \mathrm{XX}[4]\end{array}$ & - & + \\
\hline 12 & $46, \mathrm{XY}[21]$ & - & - & $44 \sim 45, \mathrm{X},-\mathrm{Y}[\mathrm{cp} 12]$ & - & - \\
\hline 13 & $\begin{array}{l}\text { 46,XY,add(4)(q35), add(5) } \\
(\mathrm{q} 31)[4] / 46, \mathrm{XY}[19]\end{array}$ & - & - & $\begin{array}{c}\text { 44 46,XY,add(4)(q35) } \\
{[\mathrm{cp} 3] / 46, \mathrm{XY}, \operatorname{add}(5)(\mathrm{q} 31)} \\
{[2] / 46, \mathrm{XY}[11]}\end{array}$ & - & + \\
\hline 14 & $46, X Y[21]$ & - & - & $46, X Y[9]$ & - & - \\
\hline 15 & $\begin{array}{c}39 \sim 46, \mathrm{XX},-18[- \\
\mathrm{cp} 3] / 44 \sim 45, \mathrm{XX}, \operatorname{del}(6)(\mathrm{q} ? \mathrm{q} ?) \\
{[\mathrm{cp} 2] / 46, \mathrm{XX}[16]}\end{array}$ & + & + & $\begin{array}{c}\text { 46,X,idic }(\mathrm{X})(\mathrm{q} 13)[4] / \\
\text { 47,idem,+X[2]/46,XX, } \\
\operatorname{del}(6)(\mathrm{q} ? \mathrm{q} ?)[2] / 46, \mathrm{XX}[2]\end{array}$ & + & - \\
\hline 16 & $\begin{array}{l}42 \sim 45, \mathrm{XY},-18[\mathrm{cp} 3] / \\
46, \mathrm{XY}[20]\end{array}$ & + & + & * & - & - \\
\hline 17 & $\begin{array}{c}41 \sim 45, \mathrm{XX},-\mathrm{X}[5],-20[3],-21[3] \\
{[\mathrm{cp} 11] / 46, \mathrm{XX}[21]}\end{array}$ & - & - & $46, \mathrm{XX}[15]$ & - & - \\
\hline 18 & $46, X Y[13]$ & + & - & $46, X Y[16]$ & - & - \\
\hline 19 & $\begin{array}{l}44 \sim 46, X X,-12[- \\
\text { cp3]/46,XX[19] }\end{array}$ & + & + & $\begin{array}{c}44 \sim 46, \mathrm{XX}, \operatorname{del}(5)(\mathrm{q} 23)[3], \\
\operatorname{del}(7)(\mathrm{q} 22)[2], \operatorname{del}(15) \\
(\mathrm{q} 21)[6], \operatorname{del}(20)(\mathrm{q} 11.2)[6] \\
{[\mathrm{cp} 6] / 46, \mathrm{XX}[2]}\end{array}$ & + & + \\
\hline
\end{tabular}

hem de kemik iliği örneklerinde uygulanan iFISH analizinde de pozitif olarak saptandı (Resim 1).

\section{TARTIŞMA}

MDS olgularında konvansiyonel sitogenetik, kromozom anomalilerini belirlemede en sık kullanılan inceleme yöntemidir (13). Ancak, yeterli sayı ve kaliteli metafaz elde etmenin güç olduğu durumlarda, sık görülen anomalilerin saptanmasında iFISH yöntemi de etkili olarak kullanılmaktadır. Her iki yöntem için tercih edilen örnek materyali genellikle kemik iliği olmakla birlikte, daha kolay elde edilen perifer kanı örneklerinin bu amaçla kullanılabilirliği araştırma konusudur. Bu çalışmalarda, kemik iliği örneğinin, özellikle tanı aşamasında konvansiyonel sitogenetikle çalışılmasının önemi üzerinde durulmakta, perifer kanının ise, hastalığın izleminde bilinen anomalilerin iFISH yöntemiyle taranarak, tekrarlayan kemik iliği aspirasyonlarından kaçınmakta yardımcı olabileceği öne sürülmektedir $(8,9,10)$. 
a

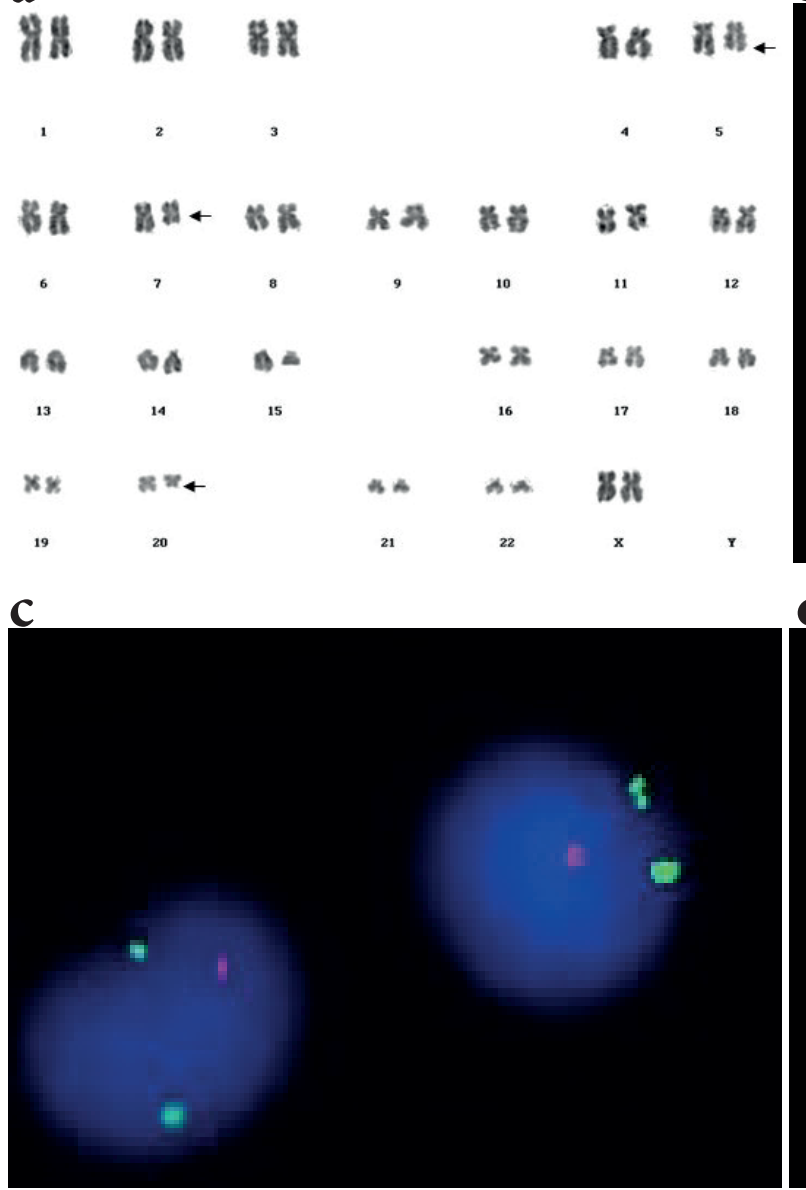

b

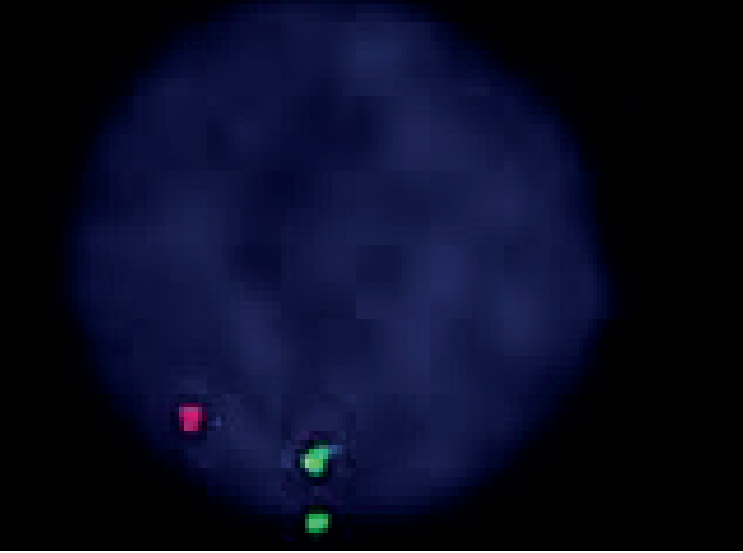

d

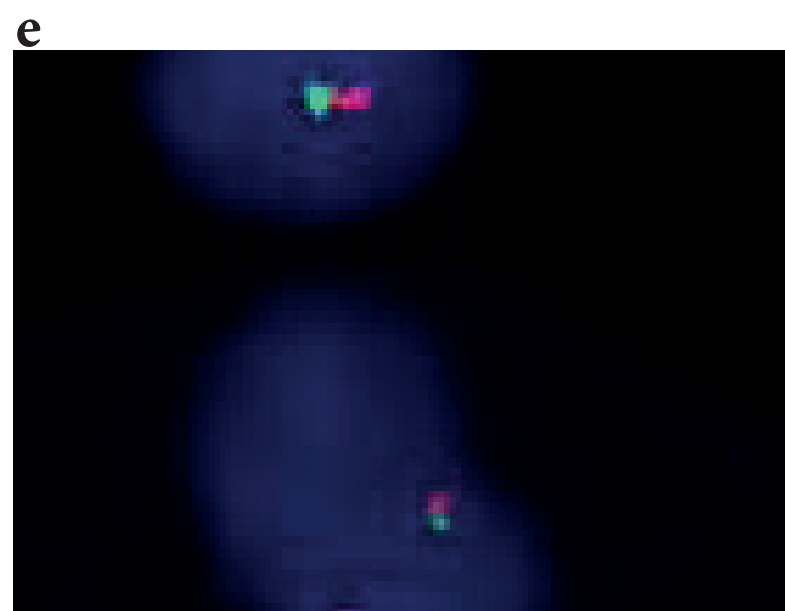

Resim 1. Olgu 19’a ait karyogram ve iFISH görüntüleri. a) Kemik iliği örneğine ait 46,XX,del(5)(q31),del(7)(q22),del(15) (q21), del(20)(q11.2) karyotipini gösteren karyogram. b) Perifer kan örneğine ait del(5q) gösteren interfaz nükleusu (Yeşil sinyal: Kontrol bölgesi; 5p15, Kırmızı sinyal: Delesyon bölgesi; 5q31 (EGR1 geni)). c) Kemik iliği örneğine ait del(5q) gösteren interfaz nükleusları. d) Perifer kan örneğine ait del(7q22) gösteren interfaz nukleusları (soldaki terminal, sağdaki ara delesyon) (Yeşil sinyal: 7q31 (MET geni), Kırmızı sinyal: 7q22 (RELN geni)). e) Kemik iliği örneğine ait biri normal (alttaki), biri del(7q22) gösteren (üstteki) interfaz nukleusları. 
Çalışmamızda, MDS tanısı alan hastalardan alınan perifer kanı ve kemik iliği aspirasyon örnekleri, konvansiyonel sitogenetik ve 5q31, 7q22 ve 7q31 bölgelerine özgü FISH probları ile incelenmiş ve her iki yöntemle elde edilen sonuçların, perifer kanı ve kemik iliği arasında gösterdiği diskordans oranları (konvansiyonel sitogenetik incelemesinde 12/17 olgu (\%70), iFISH incelemesinde -5/del5q için 6/19 (\%32), -7/del7q için $9 / 19$ olgu (\%47)) literatürde bildirilen oranlardan daha yüksek olarak saptanmıştır $(8,9,10)$. Cherry ve ark. (8) 100 olgu içeren serilerinde kemik iliği ve perifer kanı arasındaki diskordans oranlarını konvansiyonel sitogenetik incelemesinde \%6,6 ve FISH çalışmalarında \%3 olarak bildirmişlerdir. Coleman ve ark. (9) toplam 433 olgunun katılımıyla yaptıkları çalışmalarında, konvansiyonel sitogenetik ve FISH sonuçları arasında \%4-7, kemik iliği ve perifer kanı FISH sonuçları arasında ise \%31 oranında diskordans gözlemişlerdir. Fakhr ve ark. (10) ise, 35 olguyu kapsayan çalışmalarında kemik iliği ve perifer kanı arasında sitogenetik incelemede \%26 diskordans gözlenirken, FISH analizinde hiç diskordans saptanmadığını bildirmişlerdir. Bu durumun, çalışmamızın en önemli limitasyonu olan olgu sayısının azlığına bağlı olabileceğini ve daha fazla sayıda hasta üzerinde çalışmanın gerekli olduğunu düşünmekteyiz.

\section{SONUÇ}

Sonuç olarak, daha önce yapılan çalışmalarla bizim sonuçlarımız birlikte değerlendirildiğinde, her iki yöntem ve her iki örneğin kendilerine özgü avantajlara ve dezavantajlara sahip oldukları ve birbirlerinin yerini almak yerine, paralel olarak kullanılmalarının MDS'nin klinik izleminde yarar sağlayacağ

Hakem Değerlendirmesi: Dış bağımsız.

Peer Review: Externally peer-reviewed.

Bilgilendirilmiş Onam: Katılımcılardan bilgilendirilmiş onam alınmıștır.

Informed Consent: Written consent was obtained from the participants.

Etik Komite Onayı: Bu çalışma için etik komite onayı İstanbul Üniversitesi Cerrahpaşa, Cerrahpaşa Tıp Fakültesi Etik Kurulu’ndan alınmıştır.
Ethics Committee Approval: This study was approved by the Ethical Committee of the Istanbul University-Cerrahpasa, Cerrahpasa Faculty of Medicine.

Yazar Katkıları: Çalışma Konsepti/Tasarım- S.H., S.C.; Veri Toplama- S.C., S.Ö.; Veri Analizi/Yorumlama-S.C., Ş.Y., R.D.K., A.Ç., Y.T.A.; Yazı Taslağ1- S.C., A.Ç.; İçeriğin Eleştirel İncelemesi- Y.T.A., Ş.Y., R.D.K.; Son Onay ve Sorumluluk- S.C., Ş.Y., A.Ç., R.D.K., Y.T.A., Ş.Ö., S.H.

Author Contributions: Conception/Design of Study- S.H., S.C.; Data Acquisition- S.C., S.Ö.; Data Analysis/Interpretation- S.C., Ş.Y., R.D.K., A.Ç., Y.T.A.; Drafting Manuscript- S.C., A.Ç.; Critical Revision of Manuscript- Y.T.A., Ş.Y., R.D.K.; Final Approval and Accountability- S.C., Ş.Y., A.Ç., R.D.K., Y.T.A., Ş.Ö., S.H.

Çıkar Çatışması: Yazarlar çıkar çatışması beyan etmemişlerdir

Conflict of Interest: Authors declared no conflict of interest.

Finansal Destek: Bu çalışma, İstanbul Üniversitesi Bilimsel Araştırma Projeleri Birimi (BAP) tarafindan desteklenmiştir. (Proje No: 33364)

Financial Disclosure: This study was supported by Istanbul University Scientific Research Projects Unit (BAP). (Project No: 33364).

\section{KAYNAKLAR/REFERENCES}

1. Haferlach T. The Molecular Pathology of Myelodysplastic Syndrome. Pathobiology 2019;86(1):24-9.

2. Bejar R, Levine R, Ebert B.L. Unraveling the Molecular Pathophysiology of Myelodysplastic Syndromes. J Clin Oncol 2011;29(5): 504-15.

3. Neaim F, Rao P.N, Grody W. Hematopathology, 1st ed., Academic Press. Published by Elsevier Science \& Technology 2008.

4. Saitoh K, Miura I. Fluorescence in situ hybridization of progenitor cells obtained by Fluorescence-Activated Cell sorting for the detection of cells affected by hormosome abnormality trisomy 8 in patients with myelodisplastic syndromes. Blood 1998; 92(8): 2886-92. 
5. Adema V, Hernandez J, Abáigar $M$, et al. Application of FISH 7q in MDS patients without monosomy 7 or $7 \mathrm{q}$ deletion by conventional G-banding cytogenetics: Does -7/7q- detection by FISH have prognostic value? Leuk Res 2013; 37(4): 416-21.

6. Pellagatti A, Boultwood J. The molecular pathogenesis of the myelodysplastic syndromes. Eur J Haematol 2015;95(1):3-15.

7. Sebaa A, Ades L, Penther D, et al. Incidence of $17 p$ Deletions and TP53 Mutation in Myelodysplastic Syndrome and Acute Myeloid Leukemia with 5q Deletion. Genes Chromosomes Cancer 2012; 51(12):1086-92.

8. Cherry A, Slovak M, Campbell L, et al. Will a peripheral blood $(\mathrm{PB})$ sample yield the same diagnostic and prognostic cytogenetic data as the concomitant bone marrow (BM) in myelodysplasia? Leukemia Research 2012; 36(7): 832-40.

9. Coleman J, Theil K, et al. Diagnostic yield of bone marrow and peripheral blood FISH panel testing in clinically suspected myelodisplastic syndromes and/or acute myeloid leukemia. Am J Clin Pathol 2011;135(6):915-20.

10. Fakhr ZA, Mehrzad V, İzaditabar A, Salehi M. Evaluation of the utility of peripheral blood vs bone marrow in karyotype and fluorescence in situ hybridization for myelodysplastic syndrome diagnosis. J Clin Lab Anal 2018;32:e22586.

11. McGowan-Jordan J, Simons A, Schmid M (Eds):: An International System for Human Cytogenomic Nomenclature (2016). Basel: Karger; 2016.

12. Dowling PK. Mathematics for the cytogenetic technologist. In: The AGT Cytogenetics Laboratory Manual [Internet]. John Wiley \& Sons, Ltd; 2017. p. 937-64.

13. Lai $Y$, Huang X ve ark. Standardized fluorescence in situ hybridization testing based on an appropriate panel of probes more effectively identifies common cytogenetic abnormalities in myelodysplastic syndromes than conventional cytogenetic analysis: A multicenter prospective study of 2302 patients in China. Leukemia Research 2013; 39(5): 530-5. 